\title{
Cyclin-Dependent Kinase 5 Is Required for Control of Neuroblast Migration in the Postnatal Subventricular Zone
}

\author{
Yuki Hirota, ${ }^{1,2,3}$ Toshio Ohshima, ${ }^{4,5}$ Naoko Kaneko, ${ }^{1,2,3}$ Makiko Ikeda, ${ }^{1}$ Takuji Iwasato, ${ }^{6}$ Ashok B. Kulkarni, ${ }^{7}$ \\ Katsuhiko Mikoshiba, ${ }^{5}$ Hideyuki Okano, ${ }^{3,8}$ and Kazunobu Sawamoto ${ }^{1,2,3}$ \\ ${ }^{1}$ Department of Developmental and Regenerative Biology, Institute of Molecular Medicine, Nagoya City University Graduate School of Medical Sciences, \\ Nagoya 467-8601, Japan, ${ }^{2}$ Bridgestone Laboratory of Developmental and Regenerative Neurobiology and ${ }^{3}$ Department of Physiology, Keio University \\ School of Medicine, Tokyo 160-8582, Japan, ${ }^{4}$ Department of Life Science and Medical Bio-Science, Waseda University, Tokyo 169-8555, Japan, ${ }^{5}$ Laboratory

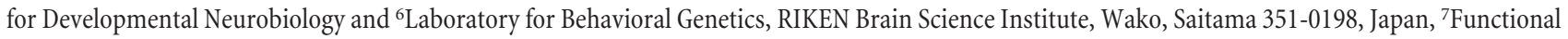 \\ Genomics Section, Craniofacial Developmental Biology and Regeneration Branch, National Institute of Dental and Craniofacial Research, National \\ Institutes of Health, Bethesda, Maryland 20892, and ${ }^{8}$ Solution Oriented Research for Science and Technology, Japan Science and Technology Corporation, \\ Saitaima 332-0012, Japan
}

\begin{abstract}
At the lateral wall of the lateral ventricles in the adult rodent brain, neuroblasts form an extensive network of elongated cell aggregates called chains in the subventricular zone and migrate toward the olfactory bulb. The molecular mechanisms regulating this migration of neuroblasts are essentially unknown. Here, we report a novel role for cyclin-dependent kinase 5 (Cdk5), a neuronal protein kinase, in this process. Using in vitro and in vivo conditional knock-out experiments, we found that $C d k 5$ deletion impaired the chain formation, speed, directionality, and leading process extension of the neuroblasts in a cell-autonomous manner. These findings suggest that Cdk5 plays an important role in neuroblast migration in the postnatal subventricular zone.
\end{abstract}

Key words: Cdk5; neuroblast; migration; subventricular zone; rostral migratory stream; postnatal neurogenesis

\section{Introduction}

Development of the adult mammalian brain requires the precisely controlled migration of cells from the site in which they were born to their destination, where they function (Marin and Rubenstein, 2003). In the adult rodent subventricular zone (SVZ), neuroblasts are continuously generated and migrate $\sim 8$ $\mathrm{mm}$ anteriorly toward the olfactory bulb (OB) (Alvarez-Buylla and Garcia-Verdugo, 2002; Lledo et al., 2006). Neuroblasts form elongated cell aggregates called "chains," in which cells migrate tangentially within the SVZ and then enter the highly restricted route termed the rostral migratory stream (RMS) (Lois and Alvarez-Buylla, 1994; Wichterle et al., 1997). Extracellular and transmembrane proteins have been implicated in the control of this neuroblast migration, which occurs at high speed over a long distance; these proteins include Slit ( $\mathrm{Hu}, 1999$; Wu et al., 1999; Sawamoto et al., 2006), Prokineticin (Ng et al., 2005), Eph

Received March 6, 2007; revised 0ct. 1, 2007; accepted 0ct. 3, 2007.

This work was supported by grants from Bridgestone Corporation, The Ministry of Education, Culture, Sports, Science, and Technology, the Ministry of Health, Labor, and Welfare, the Toray Science Foundation, the Naito Foundation, and Keio University Medical Science Fund. Y.H. was a Japan Society for the Promotion of Science Research fellow. N.K. is an Inoue fellow. We are grateful to Jun-ichi Miyazaki for the CAG-CAT-Z mice, Atsushi Iwama and Satoru Miyagi for the Cre-IRES-GFP and IRES-GFP retrovirus vectors, Jane Wu and Yi Rao for the xSlit expression vector, and Hidenori Tabata, Takahiko Kawasaki, Tatsumi Hirata, Atsushi Tamada, Fujio Murakami, Hynek Wichterle, and Arturo Alvarez-Buylla for technical advice.

Correspondence should be addressed to Kazunobu Sawamoto, Department of Developmental and Regenerative Biology, Institute of Molecular Medicine, Nagoya City University Graduate School of Medical Sciences, Nagoya 4678601, Japan. E-mail: sawamoto@med.nagoya-cu.ac.jp.

DOI:10.1523/JNEUROSCI.1014-07.2007

Copyright $\odot 2007$ Society for Neuroscience 0270-6474/07/2712829-10\$15.00/0
(Conover et al., 2000), ErbB4 (Anton et al., 2004), deleted in colorectal cancer (Murase and Horwitz, 2002), integrin (Emsley and Hagg, 2003; Belvindrah et al., 2007), and polysialylated neural cell adhesion molecule ( $\mathrm{Hu}$ et al., 1996). In addition, the subsequent reorganization of the cytoskeletal architecture mediated by intracellular proteins such as Doublecortin (Dcx) (Koizumi et al., 2006), cell division cycle 42 (Wong et al., 2001), srGAPs (slitrobo GTPase activating proteins) (Wong et al., 2001), and nonmuscle myosin II (Schaar and McConnell, 2005) may be a key step for the coordinated migration of neuroblasts. However, the molecular mechanisms regulating the cytoskeletal dynamics during neuroblast migration in the adult brain are essentially unknown.

Cdk5 is a member of the cyclin-dependent kinase (cdk) family and regulates multiple cellular processes of both the developing and mature CNS. Unlike other members of the Cdk family, the kinase activity of Cdk5 is triggered by its binding to p35 and p39 (Tsai et al., 1994; Tang et al., 1995) and not to cyclins. Previous studies reported that $\mathrm{Cdk} 5$-mediated cytoskeletal changes have essential roles in neuronal migration during embryonic brain development (Ohshima et al., 1996b; Gilmore et al., 1998; Ohshima et al., 2002, 2007). In addition, Cdk5 has a cell-autonomous function for migration of postnatal cerebellar granule cells (Ohshima et al., 1999). However, it remains unknown whether Cdk5 is involved in neuronal migration in the postnatal SVZ, because $C d k 5$ knock-out (KO) mice die as embryos. Here, we studied the effects of $C d k 5 \mathrm{KO}$ on the migration of neuroblasts in the postnatal SVZ and RMS using in vitro and in vivo experiments. 


\section{Materials and Methods}

Animals. Wild-type ICR and C57BL/6 mice were purchased from SLC (Shizuoka, Japan). CAG-CAT-Z mice (Sakai and Miyazaki, 1997) were provided by Dr. Jun-ichi Miyazaki (Osaka University Medical School, Suita, Osaka, Japan) and used as the Cre/loxP recombination reporter. Emx1 (empty spiracles homolog 1)-Cre mice and mice homozygous for a floxed $C d k 5$ allele ( $f C d k 5 / f C d k 5$ ) were described previously (Iwasato et

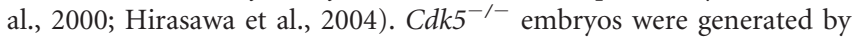
crosses between $\mathrm{Cdk5}^{+/-}$parents [day of plug was embryonic day 0.5 (E0.5)] and genotyped as described previously (Ohshima et al., 2002). Because no phenotypic difference has been identified between $C d k 5^{+/+}$ and $C d k 5^{+/-}$mice, both $C d k 5^{+/+}$and $C d k 5^{+/-}$mice were used as controls in this study. Emxl-Cre/+ mice were crossed with $C d k 5^{+/-}$mice to generate Emxl-Cre/+; $C d k 5^{+/-}$mice. The Emxl-mediated $C d k 5$ conditional KO mice (Emx1-Cre/+; $\left.f C d k 5 / C d k 5^{-}\right)$were obtained from crosses between Emxl-Cre/+; $C d k 5^{+/-}$mice and $f C d k 5 / f C d k 5$ mice and genotyped as described previously (Hirasawa et al., 2004; Ohshima et al., 2005). All experiments on live animals were performed in accordance with the guidelines and regulations of Keio University and Nagoya City University.

Histological analysis. Brains were perfused with $4 \%$ paraformaldehyde in $0.1 \mathrm{M}$ phosphate buffer, postfixed in the same fixative overnight, and then cut into 50 or $60 \mu \mathrm{m}$ sections on a vibratome. The areas of the RMS (the region between the rostral tip of the corpus callosum and the caudal end of the $\mathrm{OB}$ ) and the SVZ were measured using Photoshop (Adobe Systems, San Jose, CA) on every fourth $50-\mu$ m-thick coronal section, which was stained with cresyl violet. Because the corpus callosum and the caudal end of the OB were unclear in the Emx1-mediated Cdk5 conditional $\mathrm{KO}$ (Ckd5 ECKO) brains, the OB and RMS areas in these brains were defined according to the proportions of these areas to the whole brain in the control. The RMS and SVZ are easily distinguishable from the surrounding tissue because of their higher cell density. The volumes of the RMS and the SVZ were calculated by multiplying the areas of the RMS and SVZ measured in these sections by the $200 \mu \mathrm{m}$ thickness of four slices and summing the obtained values. For immunostaining, after being rinsed thrice in PBS, the sections were incubated for $1 \mathrm{~h}$ in blocking solution (10\% donkey serum and $0.5 \%$ Triton X-100 in PBS), overnight with the primary antibodies, and for $2 \mathrm{~h}$ at room temperature with a biotinylated secondary antibody (1:500) or an Alexa Fluor-conjugated secondary antibody (1:300; Invitrogen, Carlsbad, CA). The biotinylated antibodies were visualized using the Vectastain Elite ABC kit (Vector Laboratories, Burlingame, CA). The following primary antibodies were used: rabbit anti- $\beta$-galactosidase antibody, 1:2000 (Biogenesis, Poole, UK); mouse anti-GFAP antibody, 1:200 (Sigma, St. Louis, MO); mouse anti-Mash1 (mammalian achaete-scute homolog 1) antibody, 1:100 (PharMingen, San Diego, CA); goat anti-Dcx antibody, 1:200 (Santa Cruz Biotechnology, Santa Cruz, CA); rat anti-bromodeoxyuridine (BrdU) antibody, 1:100 (AbCam, Cambridge, MA); rabbit anti-Ki67 antibody, 1:800 (Novocastra, Newcastle upon Tyne, UK); and rabbit antigreen fluorescent protein (GFP) antibody, 1:100 (MBL, Aichi, Japan). The nuclei were stained with Hoechst. To count Dcx-positive $\left(\mathrm{Dcx}^{+}\right)$ cells, Ki67 ${ }^{+}$cells, and pyknotic cells in the SVZ of E18.5 embryos, three fields were randomly selected from optical sections at three positions (240, 480, and $720 \mu \mathrm{m}$ caudal to the rostral tip of the corpus callosum) from each brain. Whole-mount staining of the lateral wall of the lateral ventricles was performed as described previously (Doetsch and AlvarezBuylla, 1996). For in situ hybridization, digoxigenin-labeled antisense and sense riboprobes for $p 35$ were generated by the in vitro transcription of a pBluescript SK $(-)$ plasmid containing a $p 35 \mathrm{cDNA}-\mathrm{p} 5$ (Ohshima et al., 1996a) insert, using T7 and T3 RNA polymerases. In situ hybridization on paraffin sections was performed as described previously (Tanaka et al., 2001). Images were obtained using an Axioplan2 and confocal laser microscope LSM510 (Zeiss, Oberkochen, Germany).

Western blotting. SVZ and cortex tissues homogenized in a lysis buffer (50 mu Tris-HCl, pH 7.5, 10\% glycerol, 1\% Triton X-100, $150 \mathrm{~mm} \mathrm{NaCl}$, $100 \mathrm{~mm} \mathrm{NaF}, 1 \mathrm{~mm} \mathrm{Na} \mathrm{VO}_{4}, 10 \mathrm{~mm}$ EGTA, $2 \mu \mathrm{g} / \mathrm{ml}$ aprotinin, $2 \mu \mathrm{g} / \mathrm{ml}$ leupeptin, and $50 \mu \mathrm{M}$ PMSF) were separated by SDS-PAGE and blotted onto an Immobilon-P polyvinylidene difluoride membrane (Millipore,
Billerica, MA). The membranes were blocked in 5\% skim milk in PBST (0.05\% Tween 20 in PBS) for $1 \mathrm{~h}$ and probed with primary antibodies in $1 \%$ skim milk in PBST, followed by treatment with horseradishperoxidase-conjugated secondary antibodies and ECL Western blotting detection reagent (GE Healthcare, Piscataway, NJ). Signals were detected and measured with a cooled charge-coupled device camera (LAS3000mini; Fujifilm, Tokyo, Japan). The primary antibodies were rabbit anti-Cdk5, 1:500 (Santa Cruz Biotechnology) and rabbit anti- $\beta$-actin, 1:1000 (AbCam).

BrdU labeling. BrdU (10 mg/ml in PBS, $50 \mathrm{mg} / \mathrm{kg}$ body weight) was injected into mice intraperitoneally. To study cell proliferation, postnatal day 11 (P11) mice were analyzed $1 \mathrm{~h}$ after the single BrdU pulse. To study cell migration, $\mathrm{P} 13$ mice were analyzed $5 \mathrm{~d}$ after the single BrdU pulse. The numbers of BrdU ${ }^{+}$cells in the SVZ and OB were counted on every fourth $50-\mu \mathrm{m}$-thick coronal section. The total number of $\mathrm{BrdU}^{+}$cells in the SVZ and OB was estimated by multiplying the number counted in each $50-\mu \mathrm{m}$-thick section by four and summing them.

Matrigel culture. The SVZ was dissected from E18.5 embryos in L-15 medium (Invitrogen) and dissociated using trypsin-EDTA (Invitrogen). Dissociated cells were washed with L-15 medium, reaggregated by centrifugation, cut into small pieces $(300-500 \mu \mathrm{m}$ in diameter), and embedded in a 3:1 Matrigel (BD Biosciences, San Jose, CA)/L-15 mixture. The SVZ explants were then cultured with Neurobasal medium (Invitrogen) supplemented with 10\% FBS, 2 mM L-glutamine, 2\% B-27 (Invitrogen), and $50 \mathrm{U} / \mathrm{ml}$ penicillin-streptomycin, at $37^{\circ} \mathrm{C}$ in a $5 \% \mathrm{CO}_{2}$ incubator. Forty-eight hours later, the explants were fixed and processed for immunostaining and nuclear staining with the same protocol used for sections except explants were fixed for $30 \mathrm{~min}$ at room temperature. To examine the differentiation of astrocytes, the explants were cultured for $5 \mathrm{~d}$ before fixation and staining with anti-GFAP antibody. Images were obtained using an Axiovert100 and confocal laser microscope LSM5 PASCAL (Zeiss). The number of migrating cells was determined by counting the cells outside the explant perimeter. Elongated cell clusters containing more than five nuclei stained with Hoechst were defined as chains for the quantification of chain-formation efficiency. To calculate the percentage of $\mathrm{GFAP}^{+}$or Ki67 $^{+}$cells, images of explants stained with anti-GFAP or anti-Ki67 antibody with Hoechst were obtained and used for counting the number of total and labeled cells. To calculate the percentage of pyknotic cells, images of explants stained with Hoechst were obtained and used for counting the number of total and pyknotic cells.

Coculture of SVZ explants with choroid plexus or cell aggregates. The choroid plexus $(\mathrm{CP})$ was taken from the lateral ventricles of $\mathrm{P} 0-\mathrm{P} 1$ wildtype C57BL/6 mice. Human embryonic kidney HEK293T cells were transiently transfected with a plasmid expressing full-length Myc-tagged $\mathrm{Xe}$ nopus Slit (xSlit) protein (Wu et al., 1999) using FuGENE 6 transfection reagent (Roche, Mannheim, Germany). Cell aggregates of xSlitexpressing HEK293T cells were made by the hanging drop method (Kennedy et al., 1994). SVZ explants were prepared as described above, embedded with the CP or xSlit-expressing HEK293T cell aggregates in PureCol collagen (Inamed, Fremont, CA), and cultured in the same medium used in the Matrigel culture. The samples were fixed 36-40 h (for CP) and 66-70 h (for xSlit-expressing HEK293T cells) after the beginning of culture. Cell nuclei in the explants were stained with Hoechst for counting.

Time-lapse analyses of neuroblasts migrating in cultured brain slices. The transplantation of labeled cells into a brain slice was performed as described (Wichterle et al., 2003) with modifications. SVZ cells were prepared using the same protocol as for Matrigel culture (see above), except they were labeled using the PKH26 Fluorescent Cell Linker Kit (Sigma), according to the instructions of the manufacturer, immediately after dissociation. Organotypic brain slices were prepared from P4-P6 ICR mice as reported previously (Murase and Horwitz, 2002; Suzuki and Goldman, 2003) with modifications. Dissected brains were embedded in $2 \%$ low-melting-point agarose in L-15 medium and cut into sagittal slices $(270 \mu \mathrm{m}$ thick) on a Mcllwain tissue chopper. The slices were placed on a Millicell-CM membrane (Millipore), which was submerged in the same medium as in the Matrigel culture. The RMS in the slices was identified by its translucent appearance. Labeled SVZ cells were implanted into a hole produced using an ophthalmic knife at the posterior 
part of the RMS (see Fig. $5 \mathrm{~A}$ ). The slices were cultured for $33-52 \mathrm{~h}$ at $37^{\circ} \mathrm{C}$ in a $5 \% \mathrm{CO}_{2}$ incubator before the recording was started. Time-lapse video recordings were obtained using an inverted Zeiss confocal microscope LSM5 PASCAL equipped with a stage top microscope incubator INU-ZI-F1 $\left(5 \% \mathrm{CO}_{2}\right.$ at $37^{\circ} \mathrm{C}$; Tokai Hit, Shizuoka, Japan), at low magnification using a $10 \times$ dry objective lens. Every $5-10 \mathrm{~min}, 7-12$ optical Z sections (Z-steps; $10 \mu \mathrm{m}$ ) were obtained automatically over a period of $6 \mathrm{~h}$, and all of the focal planes (70-120 $\mu \mathrm{m}$ thick) were merged to visualize the shape of the entire cell. For quantification of the speed and complexity of migration (see Fig. $5 B$ ), we traced the route of all the cells found in regions closer to the $\mathrm{OB}$ relative to their starting point, every 10 min for at least $70 \mathrm{~min}$ using NIH ImageJ version 1.36 software. To avoid unhealthy cells, neuroblasts migrating at $<30.0 \mu \mathrm{m} / \mathrm{h}$ were excluded from the analyses. To compare the number of cells migrating in the forward direction (see Fig. $5 C-E$ ), the positions of cell bodies before and after a 1-h culture were recorded. Neuroblasts moving in a direction within a $60^{\circ}$ angle toward the OB were classified as "forward directed," and those in all other directions were considered "non-forward directed" (see Fig. 5C).

Retrovirus production and injection. The Cre-internal ribosomal entry site (IRES)-GFP- and IRES-GFP-encoding retroviruses were kindly provided by Dr. Atsushi Iwama (Chiba University, Chiba, Japan). Concentrated and purified virus stocks $\left(1.0 \times 10^{6}-10^{7}\right.$ viral particles $\left./ \mathrm{ml}\right)$ were prepared using standard procedures. An $800 \mathrm{nl}$ volume of the viral suspension was stereotaxically injected into the SVZ bilaterally at the position [(relative to bregma) anterior, lateral, and depth (in $\mathrm{mm}$ ): 1.1, 0.9, and $1.8-3.4]$ of the $f C d k 5 / f C d k 5$ transgenic mice. To analyze the distribution of the virus-infected cells, we counted all of the GFP ${ }^{+}$cells (total number of infected cells: IRES-GFP, 14,216 cells in three hemispheres; Cre-IRES-GFP, 8020 cells in four hemispheres) in the SVZ, RMS, and OB. To examine the morphology of virus-infected cells, we excluded the virus-infected cells within $50 \mu \mathrm{m}$ of the injection site, to avoid effects attributable to injury caused by the injection.

Statistical analyses. All data were expressed as the mean \pm SEM. Differences between means were determined by paired two-tailed Student's $t$ tests. The frequencies of neuroblasts migrating in the forward or nonforward directions and the number of $\mathrm{BrdU}^{+}$cells at $1 \mathrm{~h}$ or $5 \mathrm{~d}$ after injection were compared using $\chi^{2}$ analysis. A $p$ value of $<0.05$ was considered significant.

\section{Results \\ Accumulation of neuroblasts in the RMS and SVZ of Emx1- Cre-mediated Cdk5 conditional $\mathrm{KO}$ mice}

Cdk5 is ubiquitously expressed in the CNS (Zheng et al., 1998) and is activated by binding to its activators p35 and p39 (Tsai et al., 1994; Tang et al., 1995). p35 is expressed in both young and mature neurons (Tsai et al., 1994; Zheng et al., 1998). We performed in situ hybridization on mouse brain sections and detected p35 mRNA in the adult RMS (supplemental Fig. 1, available at www.jneurosci.org as supplemental material), suggesting that Cdk5 is activated in this region. Indeed, the phosphorylation activity of Cdk5 in the RMS has been directly demonstrated using an in vitro kinase assay (Paratcha et al., 2006). To investigate whether $C d k 5$ deletion affects neuroblast migration in the RMS, $f C d k 5 / f C d k 5$ mice were crossed with Emx1-Cre/+ mice, in which Cre is expressed in the dorsal region of the telencephalon (Iwasato et al., 2000). To confirm that the Cre-mediated deletion of a floxed gene could be induced in the SVZ cells of Emx1-Cre mice, we prepared brain sections of the SVZ-RMS-OB region of P0 and P10 double-transgenic mice carrying both Emx1-Cre and $C A G-C A T-Z$ constructs, and stained them with antibodies against $\beta$-galactosidase combined with anti-Dcx (type A cell marker) (Gleeson et al., 1999; Brown et al., 2003), anti-GFAP (type B cell marker) (Doetsch et al., 1999), or anti-Mash1 (type C cell marker) (Parras et al., 2004; Sakaguchi et al., 2006). We found that a subpopulation of each of these cell types expressed $\beta$-galactosidase (supplemental Fig. 2, available at www. jneurosci.org as supplemental material). Consistent with our observation, two independent Emx1-Cre lines have recently been reported to express Cre in SVZ cells that generate interneurons in the OB (Kohwi et al., 2007; Young et al., 2007). Because most of the Cdk5 ECKO mice died at approximately P20, we analyzed their brains between P11 and P14. We confirmed that the amount of Cdk5 in the SVZ and cortex of the Cdk5 ECKO brains was decreased compared with the control brains by Western blotting (supplemental Fig. 3, available at www.jneurosci.org as supplemental material).

To study the morphology of the SVZ-RMS-OB pathway, sagittal and coronal brain sections were stained with cresyl violet. As we reported previously (Ohshima et al., 2007), the Cdk5 ECKO mice did not have a distinct corpus callosum (Fig. $1 B, E, F$ ), although the corpus callosum was obvious in the controls (Fig. $1 A, C, D)$. The volume of the $C d k 5$ ECKO telencephalon anterior to the hippocampus was significantly smaller than that of the control (Ohshima et al., 2007) (Fig. 1C-F) (control at P11, $15.7 \pm 0.5 \mathrm{~mm}^{3}, n=3 ; C d k 5 \mathrm{ECKO}$ at P11, $11.6 \pm 0.9 \mathrm{~mm}^{3}, n=$ $3 ; p=0.0173)$. Moreover, the proportion of the volume in this anterior part of the telencephalon represented by the $\mathrm{OB}$ that contained glomeruli was significantly smaller in the Cdk5 ECKO mice than in the controls (Fig. $1 A, B$ ) (control, $17.2 \pm 1.9 \%, n=$ 3; Cdk5 ECKO, $12.7 \pm 1.1 \%, n=3 ; p=0.0417)$, suggesting that the $\mathrm{OB}$ was more severely affected than other regions. The $C d k 5$ ECKO mice had a severely thickened RMS and SVZ (Fig. $1 B, E-$ $G)$. Quantitative analyses revealed that the volumes of the RMS (control, $0.683 \pm 0.077 \%, n=3$; Cdk5 ECKO, $1.732 \pm 0.141 \%$, $n=3 ; p=0.0028$ ) and SVZ (control, $0.592 \pm 0.043 \%, n=3$; Cdk5 ECKO, $0.992 \pm 0.090 \%, n=3 ; p=0.0161)$ were significantly increased in the $C d k 5$ ECKO mice compared with controls (Fig. $1 G$ ), suggesting the rostral migration of neuroblasts was affected.

Irregular chain formation of neuroblasts in the SVZ of Emx1mediated $C d k 5$ conditional $\mathrm{KO}$ mice

To examine the distribution of neuroblasts in the Cdk5 ECKO SVZ, we performed whole-mount staining of the lateral walls of the lateral ventricles with an antibody against Dcx. In control brains, the neuroblasts were organized into a network of compact chains oriented in parallel to the anteroposterior axis of the lateral ventricles (Fig. $1 H, J, K$ ). In contrast, in the Cdk5 ECKO brains, the morphology and orientation of the neuroblast chains were irregular (Fig. $1 I, L, M$ ). We consistently observed well organized chains aligned in parallel to the longitudinal axis of the lateral ventricles in the wild-type brains (Fig. $1 \mathrm{~K}$ ) but not in the Cdk5 ECKO brains (Fig. $1 \mathrm{M}$ ), suggesting a possible role for Cdk5 in normal chain migration. Migrating cells in the SVZ and RMS are ensheathed by glial tubes of astrocytic cells (Peretto et al., 1997; Doetsch et al., 1999). In the Cdk5 ECKO brains, the aggregates of neuroblasts included ectopic $\mathrm{GFAP}^{+}$astrocytes that were not present in control chains (data not shown), suggesting a disorganization of glial tubes that could be a cause of the defective neuroblast migration. Because Emx1-Cre was expressed not only in neuroblasts but also in $\mathrm{GFAP}^{+}$astrocytes (supplemental Fig. 2, available at www.jneurosci.org as supplemental material), both cell-autonomous and non-cell-autonomous defects in neuroblast migration could exist in Cdk5 ECKO mice. Thus, we designed and performed experiments to demonstrate more precisely the cell-autonomous function of Cdk5 in neuroblasts (see below). 

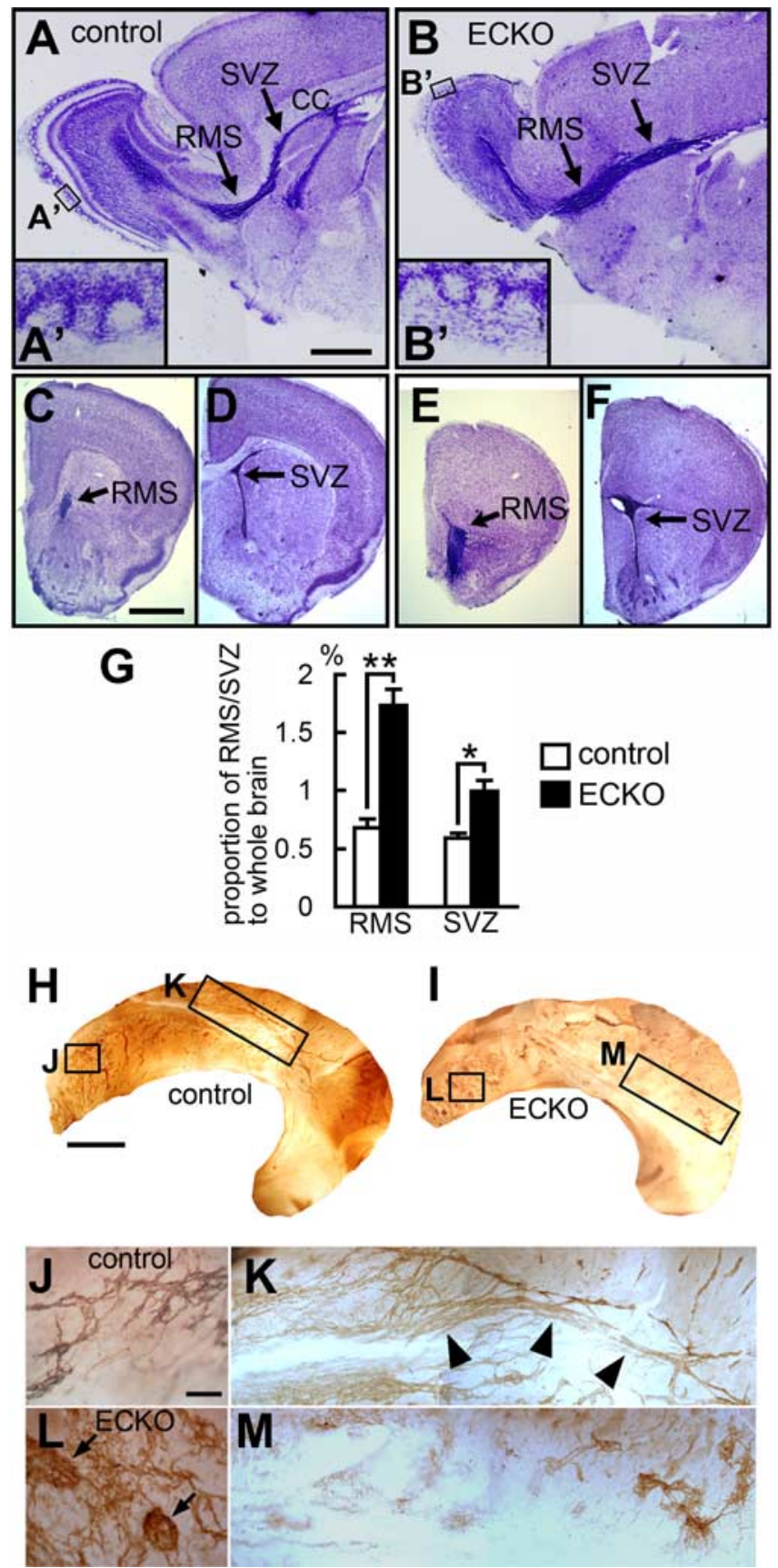

Figure 1. Emx1-Cre-mediated $C d k 5$ conditional $K 0$ causes cellular accumulation at the RMS and SVZ. $\boldsymbol{A}-\boldsymbol{F}$, Nissl-stained sagittal $(\boldsymbol{A}, \boldsymbol{B})$ and coronal $(\boldsymbol{C}-\boldsymbol{F})$ sections showing the thickened RMS and SVZ of Cdk5 ECKO mice $(\boldsymbol{B}, \boldsymbol{E}, \boldsymbol{F})$ compared with controls $(\boldsymbol{A}, \boldsymbol{C}, \boldsymbol{D})$. The Cdk5 ECKO mice did not have a distinct corpus callosum, which was clearly detected in controls (indicated by $C($ in $\boldsymbol{A}) . \boldsymbol{A}^{\prime}, \boldsymbol{B}^{\prime}$, Higher-magnification views of the glomeruli marked by rectangles in $\boldsymbol{A}$ and $\boldsymbol{B}$. $\boldsymbol{G}$, The percentages of the whole-brain volume represented by the RMS and SVZ were significantly greater in the C $d k 5$ ECKO mice than in the controls. $\mathbf{H}-\mathbf{M}$, Ectopic distribution and irregular chain formation of neuroblasts in $\mathrm{Cdk5}$ ECKO mice. Whole mounts of the lateral walls of the lateral ventricles from control $(\boldsymbol{H}, \boldsymbol{J}, \boldsymbol{K})$ and $C d k 5$ ECKO $(\boldsymbol{I}, \boldsymbol{L}, \boldsymbol{M})$ brains stained with an antibody against Dcx. Highermagnification views of the anterior horn $(J, L)$ and the intermediate bridge $(K, M)$ marked by rectangles in $\boldsymbol{H}$ and $\boldsymbol{I}$. The chains in the $\mathrm{Cdk5}$ ECKO brain were disoriented and formed irregular accumulations (arrows) ( $\boldsymbol{L}$ ), but in the control brain they were compact and oriented toward the anterior $(J)$. Chains that extended over long distances (arrowheads) were observed in the control brain $(\boldsymbol{K})$ but not in the $C d k 5$ ECKO brain $(\boldsymbol{M}) .{ }^{*} p<0.05$, ${ }^{* *} p<0.01$. Scale bars: $\boldsymbol{A}, \boldsymbol{B}, 300 \mu \mathrm{m} ; \boldsymbol{C}-\boldsymbol{F}, 300 \mu \mathrm{m} ; \boldsymbol{H}, \boldsymbol{I}, 0.5 \mathrm{~mm} ; \boldsymbol{J}-\boldsymbol{M}, 100 \mu \mathrm{m}$.
Rostral migration of neuroblasts is impaired in Emx1mediated $C d k 5$ conditional KO mice

Because Emx1-Cre is expressed in a subpopulation of each of the proliferating cell types in the SVZ (supplemental Fig. 2, available at www.jneurosci.org as supplemental material), we examined the number of BrdU-labeled cells in the Cdk5 ECKO brains. One hour after BrdU pulse labeling, there was no significant difference in the density of $\mathrm{BrdU}^{+}$cells in either the SVZ or OB (Fig. $2 A, C, E, G$ ), suggesting that the $C d k 5$ deficiency did not affect proliferation in these regions of the Cdk5 ECKO brains. Serial coronal sections from the SVZ to OB of P13 control brain $5 \mathrm{~d}$ after BrdU administration revealed that only a few labeled cells remained in the SVZ (Fig. $2 B$ ), with the majority of the labeled cells being in the OB (Fig. $2 F$ ). In contrast, more labeled cells were retained in the SVZ of the Cdk5 ECKO brain (Fig. 2D), and fewer were observed in the $\mathrm{OB}$ (Fig. $2 \mathrm{H}$ ). Furthermore, when we compared the increase in $\mathrm{BrdU}^{+}$cells in the $\mathrm{OB}$ that occurred by $5 \mathrm{~d}$ after the injection, we found a significantly smaller increase in the $C d k 5$ ECKO brain (a 7.3-fold increase) than in the control (a 9.4-fold increase) $\left(p<0.0001, \chi^{2}\right.$ analysis $)$. Consistent with this, the level of decrease in $\mathrm{BrdU}^{+}$cells in the SVZ $5 \mathrm{~d}$ after the injection compared with $1 \mathrm{~h}$ after the injection was significantly smaller in the Cdk5 ECKO brain (9.1\% decrease) than in the control $(50.0 \%$ decrease $)\left(p<0.0001, \chi^{2}\right.$ analysis). Together, these results demonstrated an impairment of rostral migration from the SVZ to OB in the Cdk5 ECKO brains.

\section{Defective chain migration of $C d k 5$-deficient neuroblasts in Matrigel culture}

The expanded RMS and deformed network of migrating neuroblasts (Fig. 1) in the Cdk5 ECKO brains suggested that Cdk5 is required for the chain migration of neuroblasts. Therefore, we compared the migration capacity of $C d k 5$-deficient cells with that of controls using Matrigel assays, which show neuroblast migration in chains in vitro (Wichterle et al., 1997). To examine whether Cdk5 deficiency affects the differentiation of neuroblasts, we labeled SVZ sections from animals of both genotypes with anti-Dcx. No significant differences in the density (control, $4483 \pm 114 / 0.001 \mathrm{~mm}^{3}, n=36$; Cdk5 KO, $4488 \pm 105 / 0.001$ $\mathrm{mm}^{3}, n=36 ; p=0.9628$ ) or percentage (control, $93.7 \pm 0.4 \%$, $n=36$; $C d k 5 \mathrm{KO}, 94.1 \pm 0.3 \%, n=36 ; p=0.2930$ ) of positive cells were seen, indicating that these brains contained similar numbers of neuroblasts in the SVZ. Nuclear staining revealed that there were no significant differences in the density (control, $3.6 \pm 1.3$ cells $/ 0.001 \mathrm{~mm}^{3}, n=36 ; C d k 5 \mathrm{KO}, 4.9 \pm 1.9$ cells $/ 0.001$ $\mathrm{mm}^{3} ; n=36 ; p=0.4736$ ) or percentage (control, $0.08 \pm 0.03 \%$; Cdk5 KO, $0.13 \pm 0.05 \% ; n=36 ; p=0.3822$ ) of pyknotic cells between the $C d k 5 \mathrm{KO}$ and control brain, suggesting that the loss of $C d k 5$ does not affect the survival of neuroblasts. To examine whether $C d k 5$ deletion affects cell proliferation in the SVZ, we compared the number of Ki67-positive proliferating cells in the SVZ sections of Cdk5-null mice with those of controls, at E18.5. We found a 1.5-fold increase in the number of $\mathrm{Ki}^{2} 7^{+}$cells in the SVZ of $C d k 5$ KO sections (control, $8.2 \pm 1.0 \%$; $C d k 5 \mathrm{KO}, 12.6 \pm$ $1.2 \% ; n=36 ; p=0.0096$ ). An increased number of proliferating cells in the developing cortex in $C d k 5 \mathrm{KO}$ mice has been reported previously (Cicero and Herrup, 2005).

To measure migration, SVZ cell aggregates from control and $C d k 5 \mathrm{KO}$ brains were embedded in Matrigel, and the number and morphology of migrating neuroblasts were examined $2 \mathrm{~d}$ after the start of the culture (Fig. 3). Virtually all of the migrating cells were positive for Dcx in both the control (Fig. 3C,E) and Cdk5 KO (Fig. $3 D, F)$ cultures, suggesting that the $C d k 5$ deletion did not affect 


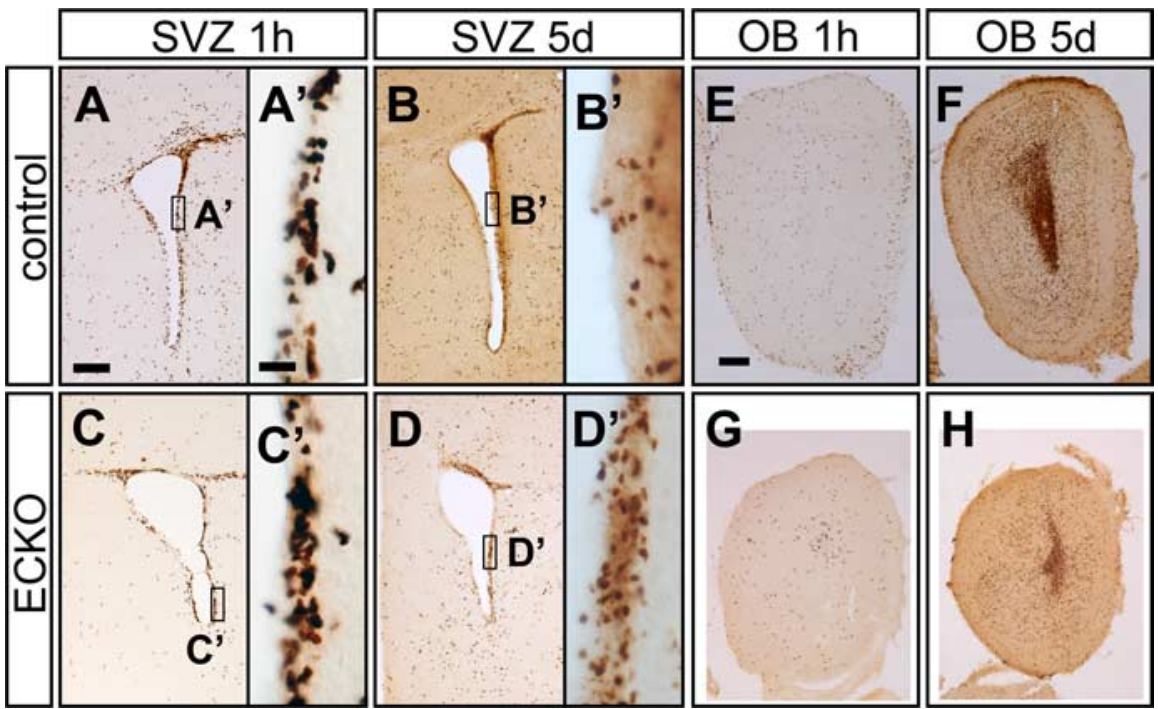

Figure 2. Emx1-mediated $C \mathrm{dk} 5$ conditional $\mathrm{K} 0$ mice have a defect in neuroblast migration, demonstrated by BrdU labeling. $A$, $C, E, G, O n e$ hour after BrdU pulse labeling. There was no significant difference in the density of BrdU ${ }^{+}$cells between $C d k 5 E C K O$ and control brains in either the SVZ ( $A, C$; control, 88,319 $\pm 16,806$ cells $/ \mathrm{mm}^{3} ;$ Cdk5 ECKO, 70,817 \pm 6089 cells $/ \mathrm{mm}^{3} ; n=3 ; p=$ 0.3829) or the $\mathrm{OB}\left(\boldsymbol{E}, \boldsymbol{G} ;\right.$ control, $4219 \pm 1513$ cells $/ \mathrm{mm}^{3} ;$; $\left(\mathrm{dk} 5 \mathrm{ECKO}, 5582 \pm 1008\right.$ cells $\left./ \mathrm{mm}^{3} ; n=3 ; p=0.4949\right) . \boldsymbol{B}, \boldsymbol{D}, \boldsymbol{F}, \boldsymbol{H}$, Five days after BrdU pulse labeling. $\boldsymbol{B}, \boldsymbol{D}$, The number of labeled cells retained in the SVZ was greater in the Cdk5 ECKO brains ( $\boldsymbol{D}$; $7380 \pm 849$ cells, $n=3$ ) than in the controls ( $\boldsymbol{B} ; 4665 \pm 401$ cells, $n=3$ ). $\boldsymbol{F}, \boldsymbol{H}$, The number of labeled cells in the OB was lower in the Cdk5 ECKO brains $(\boldsymbol{H} ; 66,472 \pm 6525$ cells, $n=3)$ than in the controls $(\boldsymbol{F} ; 119,071 \pm 7569$ cells, $n=3)$. $\boldsymbol{A}^{\prime}-\boldsymbol{D}^{\prime}$, Higher-magnification views of the portion of SVZ marked by rectangles in $\boldsymbol{A}-\boldsymbol{D}$. Scale bars: $\boldsymbol{A}-\boldsymbol{D}, \boldsymbol{E}-\boldsymbol{H}, 200 \mu \mathrm{m} ; \boldsymbol{A}^{\prime}-\boldsymbol{D}^{\prime}, 50 \mu \mathrm{m}$.

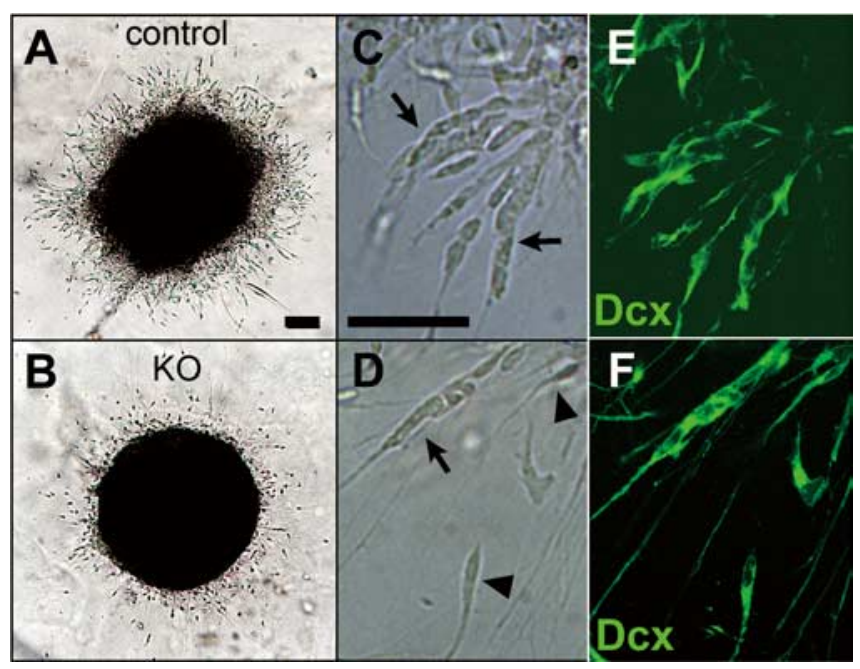

Figure 3. Decreased migration of C $d k 5 \mathrm{~K} 0$ neuroblasts cultured in Matrigel. SVZ cell aggregates from $C d k 5 \mathrm{KO}$ and control brains were cultured for $48 \mathrm{~h} . A, C$, In the control experiment, the neuroblasts migrated out of the explants and formed compact chains. $\boldsymbol{B}, \boldsymbol{D}$, There were fewer migrating neuroblasts in the $C d k 5 K 0$ cultures. $C, D$, Higher-magnification images. Cells migrating in chains and individually are indicated by arrows and arrowheads, respectively. $\boldsymbol{E}, \boldsymbol{F}$, The migrating cells in both control $(\boldsymbol{E})$ and $\mathrm{KO}(\boldsymbol{F})$ cultures expressed the neuroblast marker $\mathrm{Dcx}$. Scale bars: $A, B, 100 \mu \mathrm{m} ; C-F, 50 \mu \mathrm{m}$.

the differentiation of the neuroblasts. We also examined the effect on the differentiation of astrocytes $5 \mathrm{~d}$ after the beginning of culture. There was no significant difference in the number of $\mathrm{GFAP}^{+}$cells that migrated out of the explants between the control and $C d k 5 \mathrm{KO}$ samples (control, $4.0 \pm 0.6 \%, n=12 ; C d k 5$ $\mathrm{KO}, 3.5 \pm 0.3 \%, n=10 ; p=0.529$ ), suggesting that the loss of Cdk5 in SVZ cells did not affect the differentiation of astrocytes. We also assayed the proliferation and survival of the migrating cells in vitro. Anti-Ki67 and nuclear staining revealed no signifi- cant differences in the percentages of proliferating cells (control, $3.7 \pm 0.8 \%, n=$ 10; Cdk5 KO, $3.3 \pm 0.7 \%, n=8 ; p=$ 0.7233 ) or pyknotic cells (control, $1.38 \pm$ $0.16 \%, n=12 ; C d k 5 \mathrm{KO}, 1.58 \pm 0.32 \%$, $n=10 ; p=0.5695)$. Notably, significantly fewer cells had migrated away from the Cdk5 KO explants than from the controls (control, $519.1 \pm 52.6$ cells, $n=15 ; C d k 5$ $\mathrm{KO}, 283.6 \pm 60.6$ cells, $n=11 ; p=0.0074$ ) (Fig. $3 A, B$ ), suggesting that the $C d k 5 \mathrm{mu}$ tation impairs the neuroblast migration in vitro. Given the deformation of chains observed in the Cdk5 ECKO mice (Fig. 1), we next compared the chain formation efficiency between the control and Cdk5 KO cells. Although Cdk5 KO neuroblasts formed chains that had a normal appearance in Matrigel (Fig. 3C,D, arrows), the proportion of cells migrating individually (Fig. 3D, arrowheads) was significantly higher than in the control cultures (control, $80.6 \pm 2.9 \%, n=15 ; C d k 5 \mathrm{KO}$, $95.3 \pm 2.0 \%, n=11 ; p=0.0008)$, suggesting that Cdk5 has a role in chain formation. Taking these findings together, we conclude that Cdk5 is required for normal chain migration in vitro.

\section{Cdk5 is dispensable for the Slit-mediated repulsion} of neuroblasts

Neuroblast migration is controlled by members of the Slit family, which function as chemorepulsive factors (Wu et al., 1999; Nguyen-Ba-Charvet et al., 2004; Sawamoto et al., 2006). We therefore examined whether Cdk5 is involved in the repulsive response of neuroblasts to Slit. The CP is a source of Slit and repels migrating neuroblasts in culture (Wu et al., 1999; NguyenBa-Charvet et al., 2004). The CP from Slit1/2 double KO mice does not repel SVZ neuroblasts (Nguyen-Ba-Charvet et al., 2004) (K. Sawamoto, O. Marin, J. L. Rubenstein, M. Tessier-Lavigne, and A. Alvarez-Buylla, unpublished observation), indicating that Slit is responsible for the repulsive activity of the CP. We cocultured SVZ explants with CP in collagen gel, in which neuroblasts migrate as single cells without forming chains and are more easily counted than in Matrigel. Because the migration of neuroblasts from Cdk5 KO explants was impaired (Fig. 3), the SVZ explants were placed close to the $\mathrm{CP}$ (within $100 \mu \mathrm{m}$ ). For quantitative analysis, the region around the half of the SVZ farthest from the $\mathrm{CP}$ was divided into proximal and distal areas (Fig. 4A). Consistent with the observation in Matrigel culture, the total number of cells in the proximal and distal areas was significantly decreased for the $C d k 5 \mathrm{KO}$ explants $(282.7 \pm 30.0$ cells, $n=15)$ compared with controls ( $450.1 \pm 70.7$ cells, $n=13 ; p=0.0305)$. To assess the repulsive activity, we compared the number of migrating cells between the proximal and distal areas. A significantly lower number of cells was observed in the proximal areas in both control (196.7 \pm 36.6 cells in the proximal areas; $253.4 \pm 36.1$ cells in the distal areas; $n=13 ; p=0.0056)$ and the Cdk5 KO SVZ explants (111.3 \pm 11.1 cells in the proximal areas; $171.5 \pm 20.4$ cells in the distal areas; $n=15 ; p=0.0005$ ), indicating that the $C d k 5 \mathrm{KO}$ neuroblasts responded normally to the repulsive activity of Slit secreted from the CP (Fig. $4 B-D$ ). Similarly, $C d k 5 \mathrm{KO}$ neuroblasts were repelled when cocultured with HEK293T cells that 

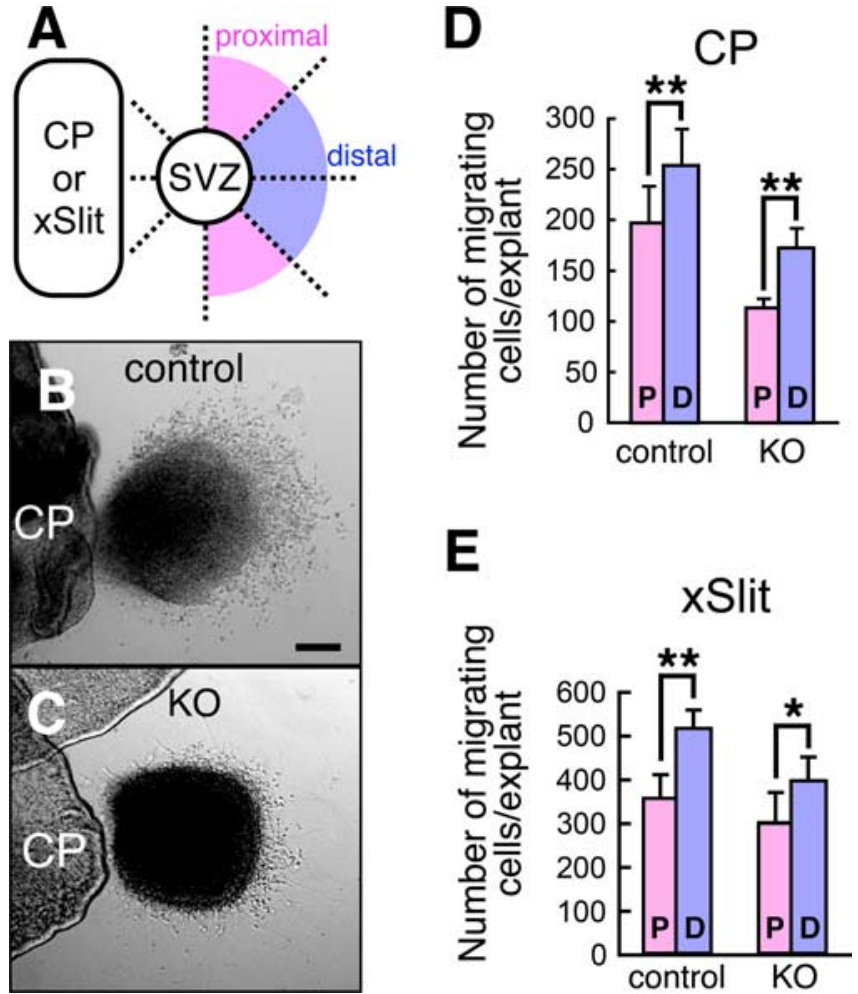

E
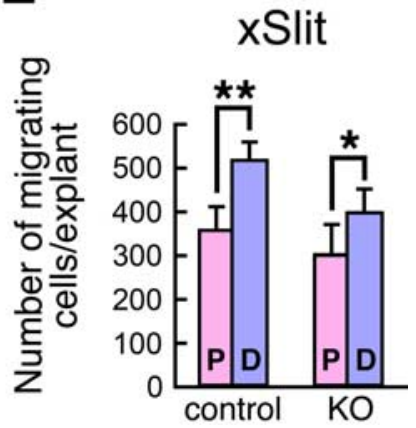

Figure 4. C $\quad d k 5 \mathrm{~K} 0$ neuroblasts respond to the repulsive activity of Slit. $A$, Schematic drawing showing the coculture system of SVZ explants with CP or xSlit-expressing HEK293T cells in collagen culture. Neuroblasts migrating in the proximal (magenta) and distal (blue) areas were counted for quantitative analyses. $\boldsymbol{B}, \boldsymbol{C}$, Phase-contrast photomicrographs of cocultures indicating that both control (B) and $C d k 5$ KO (C) neuroblasts were repelled by the CP. D, E, Quantification of the repulsive responses of control and $C d k 5 K 0$ neuroblasts to the cocultured $C P(D)$ or xSlit-expressing HEK293T (E) cells. P and D indicate the proximal and distal areas, respectively. Note that there was a significant difference in the total number of cells counted between the $C d k 5 \mathrm{KO}$ and control explants in coculture with CP (see Results). This difference was not significant in the coculture with xSlit-expressing HEK293T cells (control, $874.0 \pm 123.0$ cells, $n=4$; Cdk5 K0, $700.2 \pm 92.4$ cells, $n=5 ; p=0.2859$ ), probably because these cells had to be cultured for an extended period ( $66-70 \mathrm{~h}$ ) before the repulsive effects became evident (see Materials and Methods). ${ }^{*} p<0.05,{ }^{* *} p<0.01$. Scale bar: $\boldsymbol{B}, \boldsymbol{C}, 100 \mu \mathrm{m}$.

had been transiently transfected with xSlit (control, $356.5 \pm 54.8$ cells in the proximal areas, $517.5 \pm 69.7$ cells in the distal areas, $n=4, p=0.0073$; $C d k 5 \mathrm{KO}, 302.0 \pm 41.9$ cells in the proximal areas, $398.2 \pm 54.1$ cells in the distal areas, $n=5, p=0.0287$ ) (Fig. $4 E$ ). Together, these results indicate that Cdk5 is not required for the Slit-induced repulsion of SVZ neuroblasts cultured in collagen gel.

\section{Cell-autonomous function of Cdk5 in controlling the speed and direction of neuroblast migration, revealed by organotypic slice culture}

The findings described above suggested that the Cdk5 mutation affects the migration of neuroblasts. To test whether Cdk5 is involved in the rostrally directed migration of neuroblasts in the RMS and whether the effect of the Cdk5 deletion on migration is cell autonomous, we next studied the migration of $C d k 5 \mathrm{KO}$ neuroblasts in the RMS of cultured wild-type brain slices. Donor SVZ cells from control or Cdk5 KO brains were labeled with $\mathrm{PKH} 26$ red fluorescent dye, transplanted into the RMS of wildtype organotypic slices, and cultured for 39-58 h (Fig. 5A). For quantitative analyses, we traced and recorded the migration routes of all the labeled cells that moved toward the OB (Fig. 5B). The average migration speed was calculated by tracing the total migration route (Fig. 5B, curved lines) of individual neuroblasts over the entire observation period. Migration speed of the $C d k 5$ KO neuroblasts was significantly slower $(50.8 \pm 3.5 \mu \mathrm{m} / \mathrm{h}, n=20$ cells in five slices) than that of the control cells $(89.0 \pm 6.0 \mu \mathrm{m} / \mathrm{h}$, $n=18$ cells in four slices; $p<0.0001$ ) (Fig. $5 B$ ) (supplemental Movie 1, available at www.jneurosci.org as supplemental material). Notably, some Cdk5 KO neuroblasts showed winding migration paths (supplemental Movie 2, available at www. jneurosci.org as supplemental material). To compare the complexity of the migration routes between control and $C d k 5 \mathrm{KO}$ cells, we quantified the length of the traced migration routes per $100 \mu \mathrm{m}$ net advance (Fig. 5B, red lines). Within each $100 \mu \mathrm{m}$ segment, Cdk5 KO neuroblasts migrated over significantly longer distances compared with the controls (control, $105.0 \pm 1.0 \mu \mathrm{m}$, $n=18$ cells in four slices; $C d k 5 \mathrm{KO}, 123.3 \pm 6.0 \mu \mathrm{m}, n=20$ cells in five slices; $p=0.0075$ ) (Fig. $5 B$, red lines), suggesting that $C d k 5$ $\mathrm{KO}$ neuroblasts could not move in a straight path in the RMS.

To examine the effects of the $C d k 5$ deficiency on migratory direction more precisely, we also recorded the positions of individual migrating neuroblasts before and after culturing for $1 \mathrm{~h}$. Neuroblasts moving in a direction within a $60^{\circ}$ angle toward the OB were defined as forward-directed cells (Sawamoto et al., 2006), and those in all other directions were considered nonforward-directed cells (Fig. 5C). The C $d k 5 \mathrm{KO}$ group included a significantly greater number of non-forward-directed cells (64.0\% of 25 cells) than the controls (31.9\% of 69 cells) (Fig. $5 D, E)\left(p=0.0051, \chi^{2}\right.$ analysis). Similarly, comparisons between selected $C d k 5 \mathrm{KO}$ and control cell populations within the same range of migration speed $(30-60 \mu \mathrm{m} / \mathrm{h})$ also showed significantly more non-forward-directed cells in the Cdk5 KO group (control, 32.4\% of 37 cells; Cdk5 KO, 63.2\% of 19 cells; $p=$ $0.0278, \chi^{2}$ analysis). Therefore, the decrease in the number of forward-directed cells in the Cdk5 KO group (Fig. 5E) was not attributable to a decrease in their fast-migrating cell population. Taking these findings together, we conclude that $C d k 5$ deletion causes a disturbance in the direction and speed of neuroblast migration in a cell-autonomous manner.

\section{Cdk5-deficient neuroblasts fail to emigrate from the SVZ in vivo}

To investigate whether the $C d k 5$ deficiency cell autonomously causes the defective migration of neuroblasts in vivo, the CreIRES-GFP retroviral vector, encoding Cre and GFP, was stereotaxically injected into the SVZ of $f C d k 5 / f C d k 5$ adult mice. To avoid possible effects of different genetic backgrounds on neurogenesis in the SVZ, we injected a retrovirus vector, Cre-IRESGFP or IRES-GFP, into the SVZ of mice with the same genetic background. Twenty days later, the numbers of GFP-labeled cells in the SVZ, RMS, and OB were counted and compared with those in the control group, in which retrovirus encoding GFP only (IRES-GFP) was injected. Twenty days after the injection, more $\mathrm{GFP}^{+}$cells remained in the SVZ of the Cre-IRES-GFP-injected brains than in the control virus-injected brains (Fig. 6). Most of the $\mathrm{GFP}^{+}$cells were found in the RMS or OB in both groups (data not shown), probably because the preexisting $\mathrm{Cdk} 5$ protein enabled these cells to emigrate from the SVZ after the viral infection. To examine whether $C d k 5$ deficiency affects the terminal differentiation of interneurons, we examined the distribution and morphology of GFP-labeled cells in the OB. There was no significant difference between the control and Cdk5 conditional $\mathrm{KO}$ $(\mathrm{CKO})$ in the percentage of labeled cell bodies positioned in the RMS (control, $5.2 \pm 2.7 \%, n=3$; Cdk5 CKO, $9.3 \pm 1.4 \%, n=4$; $p=0.2060$ ), granule cell layer (control, $87.5 \pm 4.9 \%, n=3$; Cdk5 
A

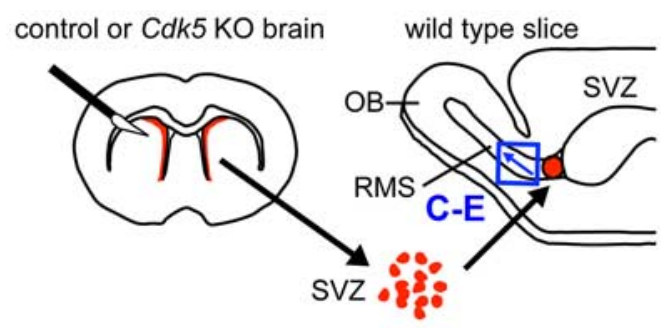

B
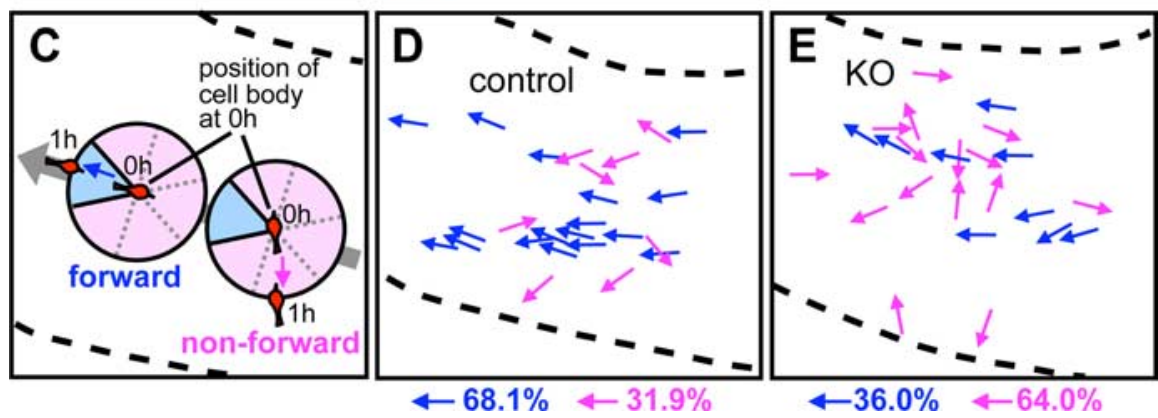

Figure 5. Cdk5 is required for the fast and directional migration of neuroblasts. $A$, Schematic drawing showing the transplant site of labeled SVZ cells in the RMS of a cultured sagittal brain slice. Time-lapse images were recorded at the region indicated by the square, rostral to the grafted cell aggregate. Blue arrow (within the square) indicates the RMS direction, which is toward the $0 \mathrm{~B}$. $\boldsymbol{B}$, Examples of the migration routes of a control (top) and a C $d k 5 \mathrm{KO}$ (bottom) neuroblast recorded for $200 \mathrm{~min}$. Blue arrow indicates the RMS direction. Gray lines indicate the positions of cell bodies at the start and end of the recordings. The speed of migration and the complexity of the migratory path were quantified on the basis of the average migration distances per hour and per $100 \mu \mathrm{m}$ net advance toward the $\mathrm{OB}$ (indicated by red curved lines in $\boldsymbol{B}$ ), respectively. $\boldsymbol{C}-\boldsymbol{E}$, Mapping of cell migration directions. $\boldsymbol{C}$, The migration direction was determined based on the positions of cell bodies recorded at 0 and $1 \mathrm{~h}$. The neuroblasts were classified into forward-directed (blue arrows) or non-forward-directed (magenta arrows) groups. Gray arrow indicates the RMS direction. Black dotted lines indicate the outline of the RMS. D, E, Composite projections showing the migration directions of control $(\boldsymbol{D})$ and $C d k 5 \mathrm{KO}(\boldsymbol{E})$ neuroblasts. The number of non-forward-directed C $d k 5 \mathrm{~K} 0$ neuroblasts was significantly larger than that of control neuroblasts.
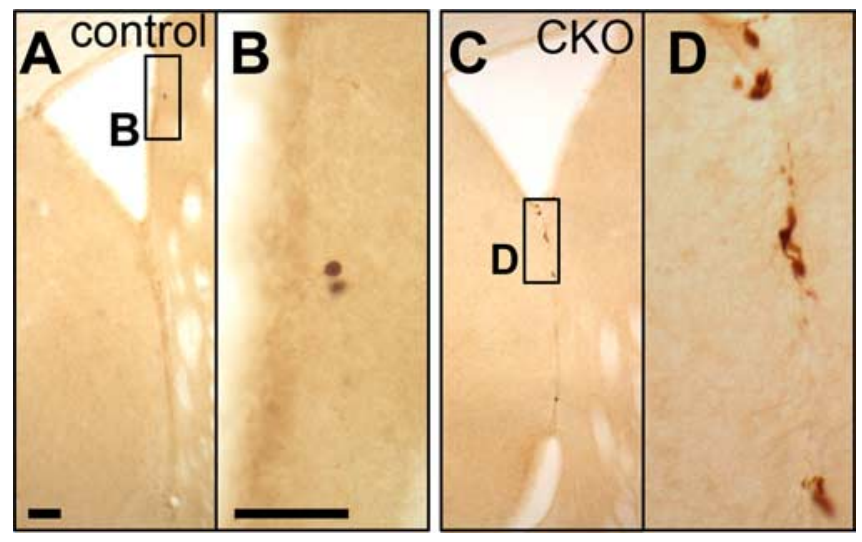

Figure 6. Conditional deletion of $C d k 5(C d k 5 C K O)$ disrupts neuroblast migration. Retroviral vectors encoding (re-IRES-GFP or IRES-GFP were injected into the SVZ of C $d k 5$ floxed mice, and the distribution and morphology of the labeled cells were analyzed $20 \mathrm{~d}$ later. $A-D$, Staining of coronal sections of IRES-GFP- $(\boldsymbol{A}, \boldsymbol{B})$ or Cre-IRES-GFP- $(\boldsymbol{C}, \boldsymbol{D})$ virus-injected brains with an antibody against GFP. $\boldsymbol{B}, \boldsymbol{D}$, Higher-magnification views of the dorsal regions marked by rectangles in $\boldsymbol{A}$ and $\boldsymbol{C}$. Scale bars: $\boldsymbol{A}, \boldsymbol{C}, 100 \mu \mathrm{m} ; \boldsymbol{B}, \boldsymbol{D}, 50 \mu \mathrm{m}$.

CKO, $79.1 \pm 2.9 \%, n=4 ; p=0.1736)$, mitral cell and external plexiform layers (control, $1.9 \pm 0.4 \%, n=3$; Cdk5 CKO, $4.1 \pm$ $0.7 \%, n=4 ; p=0.0531$ ), and periglomerular layer (control, $5.4 \pm 2.2 \%, n=3$; Cdk5 CKO, $7.5 \pm 2.5 \%, n=4 ; p=0.5790)$. The GFP-labeled cells in the Cdk5 CKO brains showed a maturated morphology similar to those in the control (data not shown). However, quantitative analysis clearly indicated that significantly more $\mathrm{GFP}^{+}$cells remained in the SVZ of the Cre-
IRES-GFP-injected brains (Fig. 6) (6.31 $1.77 \%, n=4)$ compared with the control virus-injected brains $(1.30 \pm 0.45 \%, n=$ $3 ; p=0.0218)$, suggesting that the deletion of $C d k 5$ inhibits the neuroblast migration out of the SVZ and into the RMS.

Neuroblasts have a leading process, which points toward their migration direction and has been implicated in the control of cell movement (Wichterle et al., 1997; Schaar and McConnell, 2005). We compared the length of the leading process of the $\mathrm{GFP}^{+} / \mathrm{Dcx}^{+}$neuroblasts in the SVZ between the Cre-IRES-GFP- and IRES$G F P$-injected groups (Fig. 7). The average length of the leading process of the GFP ${ }^{+}$ cells in the Cre-IRES-GFP-injected brain was significantly smaller than in the control (Fig. 7) (23.3\% decrease; control, $37.7 \pm 1.7 \mu \mathrm{m}, n=90 ; C d k 5 \mathrm{CKO}, 28.9 \pm$ $2.1 \mu \mathrm{m}, n=41 ; p=0.0026)$. There was no significant difference in the number of neuroblasts with multiple branches (control, 7 of 90 cells; Cdk5 CKO, 6 of 41 cells; $\chi^{2}$ test, $\left.p=0.2236\right)$. These results indicate that the Cdk5 deficiency impairs the leading process extension of the neuroblasts and their rostral migration in the SVZ.

\section{Discussion}

The functions of Cdk5 in neuronal migration during embryonic neural development have been extensively investigated, mainly by using $C d k 5 \mathrm{KO}$ mice. Although Cdk5 has been shown to regulate neuronal migration by phosphorylating a number of intracellular substrates (Xie et al., 2006), relatively little is known about its function in neuronal migration in the postnatal brain, probably because $C d k 5 \mathrm{KO}$ mice die as embryos. A previous study showed that cell density in the granule cell layer of the $\mathrm{OB}$ is lower than normal in NFHCre-mediated neuron-specific $C d k 5$ conditional $\mathrm{KO}$ mice (Hirasawa et al., 2004), a phenotype suggestive of impaired migration of neurons from the SVZ toward the OB. In this study, we investigated the function of Cdk5 in the SVZ-RMS-OB pathway during the postnatal period.

Here we found that the architecture and orientation of the neuroblast chains in the SVZ were severely impaired in the Cdk5 ECKO mice (Fig. 1). Emx1-Cre-mediated deletion of the Cdk5 gene affects other cell types besides neuroblasts in the dorsal telencephalon (Ohshima et al., 2005), and these deletions affect cortical development during embryogenesis (Ohshima et al., 1996b). Therefore, it is likely that the disturbed neuroblast migration in the $C d k 5$ ECKO mice reflects both cell-autonomous and non-cell-autonomous effects. We observed a large number of ectopic Dcx ${ }^{+}$neuroblasts in the striatum of the Cdk5 ECKO mice but not in the controls (data not shown). Because the Cdk5deficient cells that were infected with the Cre-IRES-GFP retrovirus were retained in the SVZ-RMS-OB pathway without entering the striatum (Fig. 6), the ectopic distribution of $\mathrm{Dcx}^{+}$cells in the striatum should be a non-cell-autonomous effect of Cdk5 ECKO. It is possible that the impaired formation of the OB, striatum, and corpus callosum observed in the C $d k 5$ ECKO brains (Fig. 1) somehow perturbed the environment or niche of the SVZ 
cells, contributing to the neuroblast migration defect. Furthermore, we compared the SVZ cells in the Cdk5 KO mice with those in control animals. There was no significant difference in the survival or differentiation of SVZ cells between the Cdk5 $\mathrm{KO}$ and control brains. A slightly increased level of proliferation was observed in the Cdk5 KO SVZ sections at E18.5 but not in the Cdk5 KO SVZ cells cultured in Matrigel or postnatal Cdk5 ECKO SVZ sections. Conversely, the defective migration of Cdk5 KO neuroblasts was consistently observed in all of our analyses, including $\mathrm{Ma}$ trigel culture (Fig. 3), slice culture (Fig. 5), and $C r e$-encoding virus-injected brains (Figs. 6, 7), as well as in the Cdk5 ECKO brains (Figs. 1, 2), suggesting that Cdk5 has an important role in neuroblast migration.

Furthermore, we developed two new
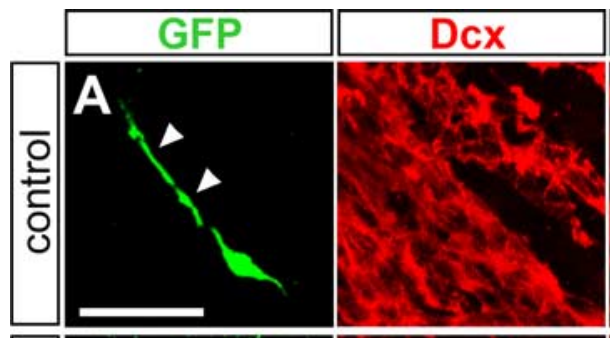

\section{GFP/Dcx}
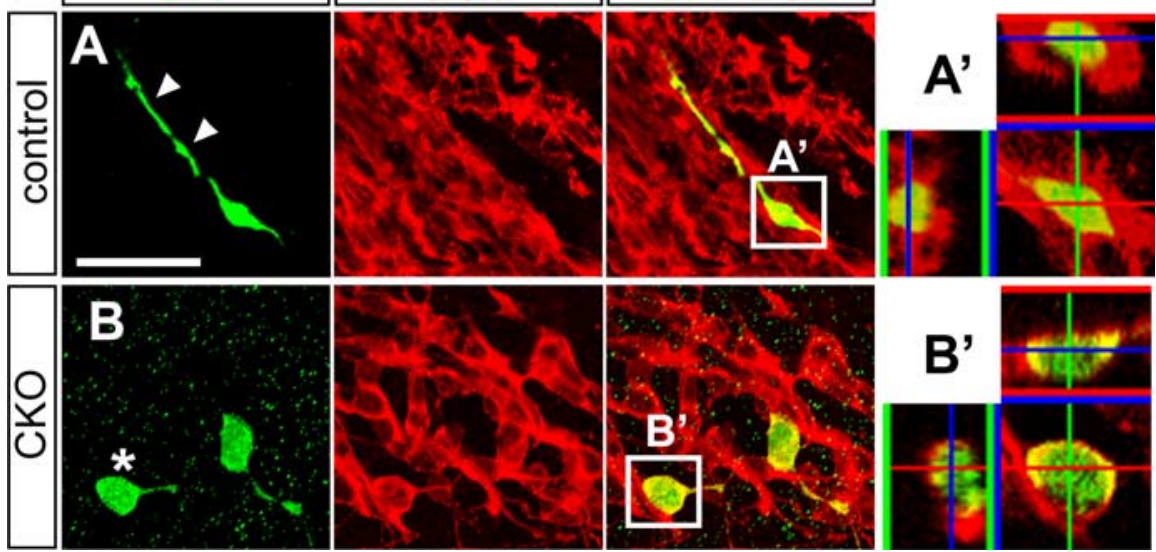

Figure 7. Double immunohistochemistry of sagittal sections containing the lateral ventricular wall, with anti-Dcx (red) and anti-GFP (green) antibodies. $\boldsymbol{A}$, In control experiments, GFP ${ }^{+}$neuroblasts extended long leading processes (arrowheads). $\boldsymbol{B}$, Neuroblasts with a short process were present in the Cre-IRES-GFP-injected brains (asterisk). $\boldsymbol{A}^{\prime}, \boldsymbol{B}^{\prime}$, Higher-magnification views and three-dimensional reconstruction images of the regions marked by squares in the merged images. Scale bar: $\boldsymbol{A}, \boldsymbol{B}, 50 \mu \mathrm{m}$. techniques that enabled us to investigate

the cell-autonomous function of $\mathrm{Cdk} 5$ in postnatal neuronal migration: (1) time-lapse recording of dissociated, labeled, and transplanted SVZ cells migrating in the RMS of a cultured brain slice and (2) Cre-encoding retrovirus-mediated gene deletion in the adult brain. Our live-imaging technique for dye-labeled neuroblasts described in this study clearly demonstrated defects in the migration speed and directionality of $C d k 5 \mathrm{KO}$ neuroblasts (Fig. 5) (supplemental Movies 1, 2, available at www.jneurosci. org as supplemental material). Injection of the Cre-encoding retrovirus into the $S V Z$ of $f C d k 5 / f C d k 5$ mice resulted in an increased number of infected neuroblasts that failed to emigrate from the SVZ (Fig. 6) and shortened their leading process (Fig. 7). These techniques will be useful to investigate specifically the cellautonomous functions of various genes in the adult brain, without affecting development. Taking these findings together, we conclude that Cdk5 has an essential role within individual neuroblasts to regulate their migration in the SVZ.

Which signal pathways are involved in the Cdk5 control of neuroblast migration? Because Cdk5 is known to function with several transmembrane receptors involved in signaling cascades, it is possible that $\mathrm{Cdk} 5$ is required for neuroblasts to respond to their guidance cues, such as Slit (Wu et al., 1999; Nguyen-BaCharvet et al., 2004; Sawamoto et al., 2006), reelin (Hack et al., 2002), tenascin (Saghatelyan et al., 2004), Netrin (Murase and Horwitz, 2002), and Prokineticin (Ng et al., 2005). Here we found that Cdk5 is dispensable for the Slit-mediated repulsion of neuroblasts (Fig. 4). The requirement of neuroblasts for Cdk5 to respond to other guidance cues needs to be investigated, to clarify the precise mechanisms of the function of Cdk5. In our experiments, $C d k 5$ deficiency was found to alter the chain-formation efficiency, the speed and direction of migration, and the length of the leading process. All these defects can be explained by an impaired regulation of cytoskeletal dynamics. Cdk5 is known to regulate the microtubule cytoskeleton via multiple phosphorylation targets: Nudel (NudE-like) (Niethammer et al., 2000), Pak1 (p21-activated kinase 1) (Rashid et al., 2001), CRMP-2 (collapsin response mediator protein-2) (Uchida et al., 2005; Yoshimura et al., 2005), Dcx (Tanaka et al., 2004), and FAK (focal adhesion kinase) (Xie et al., 2003). More recently, Cdk5 was shown to play important roles in regulating the organization of the microtubules that link the nucleus and the centrosome of migrating neu- rons in the embryonic brain (Xie et al., 2003; Tanaka et al., 2004). Microtubules are also known to be important components of the leading process (Rivas and Hatten, 1995). Maximal extension of the leading process is thought to be the critical step for initiating neuronal migration, which is followed by rapid translocation of the nucleus and centrosome positioning (Wichterle et al., 1997; Bellion et al., 2005; Schaar and McConnell, 2005). In the embryonic brain, the leading process interacts with a radial fiber, which guides the directional migration of new neurons. p35 KO neurons have an abnormally shaped leading process, which fails to interact efficiently with the radial fiber, and cannot migrate directly along the fiber (Gupta et al., 2003), suggesting a role for Cdk5 in this step. Consistent with this idea, the inactivation of the kinase activity of Cdk5 inhibits neuronal migration along radial glial fibers (Hatanaka et al., 2004). The present results suggest that Cdk5-mediated cytoskeletal regulation is involved in the extension of the leading process in the adult SVZ as well. In the chain migration of adult-born neuroblasts, the leading process interacts with other neuroblasts instead of radial fibers, which is a unique cell-migration feature found only in the mature brain. Future investigations of the phosphorylation substrates of Cdk5 during neuroblast migration will help elucidate the precise functions of Cdk5 in neuroblast migration in the postnatal brain.

In conclusion, we found that Cdk5 deletion impaired the chain formation, speed, directionality, and leading process extension of neuroblasts in a cell-autonomous manner, using new techniques. Cdk5 may therefore be one of the key factors regulating the directional and rapid migration of neuroblasts in the postnatal mouse brain.

\section{References}

Alvarez-Buylla A, Garcia-Verdugo JM (2002) Neurogenesis in adult subventricular zone. J Neurosci 22:629-634.

Anton ES, Ghashghaei HT, Weber JL, McCann C, Fischer TM, Cheung ID, Gassmann M, Messing A, Klein R, Schwab MH, Lloyd KC, Lai C (2004) Receptor tyrosine kinase ErbB4 modulates neuroblast migration and placement in the adult forebrain. Nat Neurosci 7:1319-1328.

Bellion A, Baudoin JP, Alvarez C, Bornens M, Metin C (2005) Nucleokinesis in tangentially migrating neurons comprises two alternating phases: forward migration of the Golgi/centrosome associated with centrosome splitting and myosin contraction at the rear. J Neurosci 25:5691-5699.

Belvindrah R, Hankel S, Walker J, Patton BL, Muller U (2007) $\beta 1$ integrins 
control the formation of cell chains in the adult rostral migratory stream. J Neurosci 27:2704-2717.

Brown JP, Couillard-Despres S, Cooper-Kuhn CM, Winkler J, Aigner L, Kuhn HG (2003) Transient expression of doublecortin during adult neurogenesis. J Comp Neurol 467:1-10.

Cicero S, Herrup K (2005) Cyclin-dependent kinase 5 is essential for neuronal cell cycle arrest and differentiation. J Neurosci 25:9658-9668.

Conover JC, Doetsch F, Garcia-Verdugo JM, Gale NW, Yancopoulos GD, Alvarez-Buylla A (2000) Disruption of Eph/ephrin signaling affects migration and proliferation in the adult subventricular zone. Nat Neurosci 3:1091-1097.

Doetsch F, Alvarez-Buylla A (1996) Network of tangential pathways for neuronal migration in adult mammalian brain. Proc Natl Acad Sci USA 93:14895-14900.

Doetsch F, Caille I, Lim DA, Garcia-Verdugo JM, Alvarez-Buylla A (1999) Subventricular zone astrocytes are neural stem cells in the adult mammalian brain. Cell 97:703-716.

Emsley JG, Hagg T (2003) alpha6betal integrin directs migration of neuronal precursors in adult mouse forebrain. Exp Neurol 183:273-285.

Gilmore EC, Ohshima T, Goffinet AM, Kulkarni AB, Herrup K (1998) Cyclin-dependent kinase 5-deficient mice demonstrate novel developmental arrest in cerebral cortex. J Neurosci 18:6370-6377.

Gleeson JG, Lin PT, Flanagan LA, Walsh CA (1999) Doublecortin is a microtubule-associated protein and is expressed widely by migrating neurons. Neuron 23:257-271.

Gupta A, Sanada K, Miyamoto DT, Rovelstad S, Nadarajah B, Pearlman AL, Brunstrom J, Tsai LH (2003) Layering defect in p35 deficiency is linked to improper neuronal-glial interaction in radial migration. Nat Neurosci 6:1284-1291.

Hack I, Bancila M, Loulier K, Carroll P, Cremer H (2002) Reelin is a detachment signal in tangential chain-migration during postnatal neurogenesis. Nat Neurosci 5:939-945.

Hatanaka Y, Hisanaga S, Heizmann CW, Murakami F (2004) Distinct migratory behavior of early- and late-born neurons derived from the cortical ventricular zone. J Comp Neurol 479:1-14.

Hirasawa M, Ohshima T, Takahashi S, Longenecker G, Honjo Y, Veeranna, Pant HC, Mikoshiba K, Brady RO, Kulkarni AB (2004) Perinatal abrogation of Cdk5 expression in brain results in neuronal migration defects. Proc Natl Acad Sci USA 101:6249-6254.

$\mathrm{Hu} \mathrm{H}$ (1999) Chemorepulsion of neuronal migration by Slit2 in the developing mammalian forebrain. Neuron 23:703-711.

Hu H, Tomasiewicz H, Magnuson T, Rutishauser U (1996) The role of polysialic acid in migration of olfactory bulb interneuron precursors in the subventricular zone. Neuron 16:735-743.

Iwasato T, Datwani A, Wolf AM, Nishiyama H, Taguchi Y, Tonegawa S, Knopfel T, Erzurumlu RS, Itohara S (2000) Cortex-restricted disruption of NMDAR1 impairs neuronal patterns in the barrel cortex. Nature 406:726-731.

Kennedy TE, Serafini T, de la Torre JR, Tessier-Lavigne M (1994) Netrins are diffusible chemotropic factors for commissural axons in the embryonic spinal cord. Cell 78:425-435.

Kohwi M, Petryniak MA, Long JE, Ekker M, Obata K, Yanagawa Y, Rubenstein JL, Alvarez-Buylla A (2007) A subpopulation of olfactory bulb GABAergic interneurons is derived from Emx1- and Dlx5/6-expressing progenitors. J Neurosci 27:6878-6891.

Koizumi H, Higginbotham H, Poon T, Tanaka T, Brinkman BC, Gleeson JG (2006) Doublecortin maintains bipolar shape and nuclear translocation during migration in the adult forebrain. Nat Neurosci 9:779-786.

Lledo PM, Alonso M, Grubb MS (2006) Adult neurogenesis and functional plasticity in neuronal circuits. Nat Rev Neurosci 7:179-193.

Lois C, Alvarez-Buylla A (1994) Long-distance neuronal migration in the adult mammalian brain. Science 264:1145-1148.

Marin O, Rubenstein JL (2003) Cell migration in the forebrain. Annu Rev Neurosci 26:441-483.

Murase S, Horwitz AF (2002) Deleted in colorectal carcinoma and differentially expressed integrins mediate the directional migration of neural precursors in the rostral migratory stream. J Neurosci 22:3568-3579.

Ng KL, Li JD, Cheng MY, Leslie FM, Lee AG, Zhou QY (2005) Dependence of olfactory bulb neurogenesis on prokineticin 2 signaling. Science 308:1923-1927.

Nguyen-Ba-Charvet KT, Picard-Riera N, Tessier-Lavigne M, Baron-Van Evercooren A, Sotelo C, Chedotal A (2004) Multiple roles for slits in the control of cell migration in the rostral migratory stream. J Neurosci 24:1497-1506.

Niethammer M, Smith DS, Ayala R, Peng J, Ko J, Lee MS, Morabito M, Tsai LH (2000) NUDEL is a novel Cdk5 substrate that associates with LIS1 and cytoplasmic dynein. Neuron 28:697-711.

Ohshima T, Kozak CA, Nagle JW, Pant HC, Brady RO, Kulkarni AB (1996a) Molecular cloning and chromosomal mapping of the mouse gene encoding cyclin-dependent kinase 5 regulatory subunit p35. Genomics 35:372-375.

Ohshima T, Ward JM, Huh CG, Longenecker G, Veeranna, Pant HC, Brady RO, Martin LJ, Kulkarni AB (1996b) Targeted disruption of the cyclindependent kinase 5 gene results in abnormal corticogenesis, neuronal pathology and perinatal death. Proc Natl Acad Sci USA 93:11173-11178.

Ohshima T, Gilmore EC, Longenecker G, Jacobowitz DM, Brady RO, Herrup K, Kulkarni AB (1999) Migration defects of cdk5 $5^{-1-}$ neurons in the developing cerebellum is cell autonomous. J Neurosci 19:6017-6026.

Ohshima T, Ogawa M, Takeuchi K, Takahashi S, Kulkarni AB, Mikoshiba K (2002) Cyclin-dependent kinase 5/p35 contributes synergistically with Reelin/Dab1 to the positioning of facial branchiomotor and inferior olive neurons in the developing mouse hindbrain. J Neurosci 22:4036-4044.

Ohshima T, Ogura H, Tomizawa K, Hayashi K, Suzuki H, Saito T, Kamei H, Nishi A, Bibb JA, Hisanaga S, Matsui H, Mikoshiba K (2005) Impairment of hippocampal long-term depression and defective spatial learning and memory in p35 mice. J Neurochem 94:917-925.

Ohshima T, Hirasawa M, Tabata H, Mutoh T, Adachi T, Suzuki H, Saruta K, Iwasato T, Itohara S, Hashimoto M, Nakajima K, Ogawa M, Kulkarni AB, Mikoshiba K (2007) Cdk5 is required for multipolar-to-bipolar transition during radial neuronal migration and proper dendrite development of pyramidal neurons in the cerebral cortex. Development 134:2273-2282.

Paratcha G, Ibanez CF, Ledda F (2006) GDNF is a chemoattractant factor for neuronal precursor cells in the rostral migratory stream. Mol Cell Neurosci 31:505-514.

Parras CM, Galli R, Britz O, Soares S, Galichet C, Battiste J, Johnson JE, Nakafuku M, Vescovi A, Guillemot F (2004) Mash1 specifies neurons and oligodendrocytes in the postnatal brain. EMBO J 23:4495-4505.

Peretto P, Merighi A, Fasolo A, Bonfanti L (1997) Glial tubes in the rostral migratory stream of the adult rat. Brain Res Bull 42:9-21.

Rashid T, Banerjee M, Nikolic M (2001) Phosphorylation of Pak1 by the p35/Cdk5 kinase affects neuronal morphology. J Biol Chem 276:49043-49052.

Rivas RJ, Hatten ME (1995) Motility and cytoskeletal organization of migrating cerebellar granule neurons. J Neurosci 15:981-989.

Saghatelyan A, de Chevigny A, Schachner M, Lledo PM (2004) Tenascin-R mediates activity-dependent recruitment of neuroblasts in the adult mouse forebrain. Nat Neurosci 7:347-356.

Sakaguchi M, Shingo T, Shimazaki T, Okano HJ, Shiwa M, Ishibashi S, Oguro H, Ninomiya M, Kadoya T, Horie H, Shibuya A, Mizusawa H, Poirier F, Nakauchi H, Sawamoto K, Okano H (2006) A carbohydrate-binding protein, Galectin-1, promotes proliferation of adult neural stem cells. Proc Natl Acad Sci USA 103:7112-7117.

Sakai K, Miyazaki J (1997) A transgenic mouse line that retains Cre recombinase activity in mature oocytes irrespective of the cre transgene transmission. Biochem Biophys Res Commun 237:318-324.

Sawamoto K, Wichterle H, Gonzalez-Perez O, Cholfin JA, Yamada M, Spassky N, Murcia NS, Garcia-Verdugo JM, Marin O, Rubenstein JL, Tessier-Lavigne M, Okano H, Alvarez-Buylla A (2006) New neurons follow the flow of cerebrospinal fluid in the adult brain. Science 311:629-632.

Schaar BT, McConnell SK (2005) Cytoskeletal coordination during neuronal migration. Proc Natl Acad Sci USA 102:13652-13657.

Suzuki SO, Goldman JE (2003) Multiple cell populations in the early postnatal subventricular zone take distinct migratory pathways: a dynamic study of glial and neuronal progenitor migration. J Neurosci 23:4240-4250.

Tanaka T, Veeranna, Ohshima T, Rajan P, Amin ND, Cho A, Sreenath T, Pant HC, Brady RO, Kulkarni AB (2001) Neuronal cyclin-dependent kinase 5 activity is critical for survival. J Neurosci 21:550-558.

Tanaka T, Serneo FF, Tseng HC, Kulkarni AB, Tsai LH, Gleeson JG (2004) Cdk5 phosphorylation of doublecortin ser 297 regulates its effect on neuronal migration. Neuron 41:215-227.

Tang D, Yeung J, Lee KY, Matsushita M, Matsui H, Tomizawa K, Hatase O, 
Wang JH (1995) An isoform of the neuronal cyclin-dependent kinase 5 (Cdk5) activator. J Biol Chem 270:26897-26903.

Tsai LH, Delalle I, Caviness Jr VS, Chae T, Harlow E (1994) p35 is a neuralspecific regulatory subunit of cyclin-dependent kinase 5. Nature 371:419-423.

Uchida Y, Ohshima T, Sasaki Y, Suzuki H, Yanai S, Yamashita N, Nakamura F, Takei K, Ihara Y, Mikoshiba K, Kolattukudy P, Honnorat J, Goshima Y (2005) Semaphorin3A signalling is mediated via sequential Cdk5 and GSK3beta phosphorylation of CRMP2: implication of common phosphorylating mechanism underlying axon guidance and Alzheimer's disease. Genes Cells 10:165-179.

Wichterle H, Garcia-Verdugo JM, Alvarez-Buylla A (1997) Direct evidence for homotypic, glia-independent neuronal migration. Neuron 18:779-791.

Wichterle H, Alvarez-Dolado M, Erskine L, Alvarez-Buylla A (2003) Permissive corridor and diffusible gradients direct medial ganglionic eminence cell migration to the neocortex. Proc Natl Acad Sci USA 100:727-732.

Wong K, Ren XR, Huang YZ, Xie Y, Liu G, Saito H, Tang H, Wen L, BradyKalnay SM, Mei L, Wu JY, Xiong WC, Rao Y (2001) Signal transduction in neuronal migration: roles of GTPase activating proteins and the small GTPase Cdc42 in the Slit-Robo pathway. Cell 107:209-221.
Wu W, Wong K, Chen J, Jiang Z, Dupuis S, Wu JY, Rao Y (1999) Directional guidance of neuronal migration in the olfactory system by the protein Slit. Nature 400:331-336.

Xie Z, Sanada K, Samuels BA, Shih H, Tsai LH (2003) Serine 732 phosphorylation of FAK by Cdk5 is important for microtubule organization, nuclear movement, and neuronal migration. Cell 114:469-482.

Xie Z, Samuels BA, Tsai LH (2006) Cyclin-dependent kinase 5 permits efficient cytoskeletal remodeling - a hypothesis on neuronal migration. Cereb Cortex 16 [Suppl 1]:i64-i68.

Yoshimura T, Kawano Y, Arimura N, Kawabata S, Kikuchi A, Kaibuchi K (2005) GSK-3beta regulates phosphorylation of CRMP-2 and neuronal polarity. Cell 120:137-149.

Young KM, Fogarty M, Kessaris N, Richardson WD (2007) Subventricular zone stem cells are heterogeneous with respect to their embryonic origins and neurogenic fates in the adult olfactory bulb. J Neurosci 27:8286-8296.

Zheng M, Leung CL, Liem RK (1998) Region-specific expression of cyclin-dependent kinase 5 (cdk5) and its activators, p35 and p39, in the developing and adult rat central nervous system. J Neurobiol 35: 141-159. 